\title{
ACUTE METHANOL POISENING: PROGNOSTIC FACTORS AND ROLE OF GLASGOW COMA SCALE
}

\author{
Ghada N. Mansour, M.D. ${ }^{1}$, Mohamed A. Aglan, M.D²., Mahmoud B. Abd Elwahab ${ }^{3}$. \\ ${ }^{1}$ Forensic medicine \& Clinical Toxicology Department, Faculty of medicine, Zagazig \\ University. \\ ${ }^{2}$ Forensic medicine \& Clinical Toxicology Department, Faculty of medicine, Al-Azhar \\ University. \\ 3Poison Control Centre, Ain-Shams University Hospitals.
}

\begin{abstract}
Introduction: acute methanol poisoning is one of the most important poisonings among people with low socio-economic classes who may consume illegal alcoholic beverages as it is cheap and available causing high morbidity and mortality especially in case of delayed diagnosis or treatment. This study aimed to characterize the risk factors related to mortality in patients presenting with suspected methanol poisoning and to detect the efficacy of using the GCS scoring system for prediction of mortality in these patients and identifying critically poisoned patients of high risk that need rapid and aggressive treatment.

Subjects and Methods: a prospective observational study on 51 patients with acute methanol poisoning was reported at Ain-Shams poison control center-Egypt from April 2015 to April 2017. Patients were divided according to their outcome into two groups: livings and dead.

Results: Hypotension, acute respiratory failure, pulmonary edema and CGS score were significantly associated with mortality. When assessing the risk factors significantly associated with mortality according to their priority; $\mathrm{pH} \leq 6.79$ was the most important parameter followed by GCS score $\leq 7$ and $p \mathrm{CO} 2 \geq 31.88 \mathrm{mmHg}$. There was a negative correlation between $p \mathrm{CO} 2$ and $\mathrm{pH}$ in dead. The observed mortality was not significantly different from the predicted mortality determined by GCS scoring system.

Conclusion: Hypotension, acute respiratory failure, pulmonary edema and CGS are robust markers of mortality along with $\mathrm{pH} \leq 6.79$, GCS score $\leq 7$ and $p \mathrm{CO} 2 \geq 31.88$ $\mathrm{mmHg}$. GCS scoring system could be predictive for mortality in high risk patients.

Key words: methanol, GCS, risk factors, mortality.

\section{INTRODUCTION}

wood alcohol (Methyl alcohol) is a colorless, odorless, highly toxic organic solvent (Pohanka., 2016) which is a component in many industrial solvents, photocopying fluids, washing fluids, paints removers, antifreeze formulations and perfumes (Shah et. al., 2012). Since methanol is available and cheap, it is used in the production of illegal alcoholic beverages in many developing countries (Giovanetti, 2013) causing high morbidity and

mortality in many methanol poisoned patients (Kute et. al., 2012).

Acute methanol poisoning usually occurs from intentional overdose or accidental ingestion (Pohanka, 2016). Methanol does not cause toxicity by itself and its pathological effects are caused by the accumulation of its metabolites formic acid which affects central nervous system, gastrointestinal tract and eyes causing metabolic acidosis and cellular dysfunction (Sharma et. al., 2012). Glasgow coma
\end{abstract}

Egypt J. Forensic Sci. Appli. Toxicol. 
scale (GCS) has been introduced as a scoring system since 1974 and it became widely used for prediction of the outcome of critically ill patients (Davies et. al. 2008 \& Grieb et. al., 2013).

\section{AIM OF THE WORK}

This study aimed to characterize the risk factors related to mortality in patients with suspected methanol poisoning and to detect the efficacy of GCS scoring system to identify critically poisoned patients of high risk that need rapid and aggressive treatment.

\section{SUBJECT AND METHODS}

This prospective designed study was carried out in Ain Shams Poison Control Center, Ain Shams University during the period from April 2015 up to April 2017.

\section{Subjects and groups:}

The demographic data for all studied patients as; age, sex, being habitually alcoholic, medications and medical history as well as information related to methanol poisoning as mode (intentional or unintentional) route and time of poisoning, delay since poisoning and co-ingestions (ethanol, drugs of abuse).

Subjects were chosen according to the following criteria:

Inclusion criteria:

1- Patients diagnosed as acute methanol poisoning according to history, physical or laboratory findings.

2- Positive serum-methanol level at the time of admission (samples was taken at time of admission).

Exclusion criteria:

- Patients with negative blood methanol levels.
- History of co-ingestion of ethanol or drugs of abuse that may affect consciousness.

- Patients who were managed prior admission with buffer, antidote or mechanical ventilation that could interfere with the analysis.

Awake Patients or relatives of the patients who were unconscious were informed about the study aim and the research design. An informed consent was obtained from those who agree to participate. Reassurance of confidentially was confirmed, all data were documented by a code rather than patients name. The patients were divided into two groups according to their outcome: group I, patients who survived with or without complications; group II, dead patients.

2. Methods:

On admission (prior any treatment), the GCS score was recorded for all participated patients, blood samples were withdrawn to test the following: blood-methanol level, arterial $\mathrm{pH}$, partial pressure of $\mathrm{CO} 2(p \mathrm{CO} 2)$, base deficit, bicarbonate, Osmolal gap, Anion gap and serum-creatinine.

- Blood methanol level: $10 \mathrm{~mL}$ of heparinized venous blood sample were withdrawn from each patient and kept refrigerated at $2-4^{\circ} \mathrm{C}$ and processed within 6 hours after collection with Gas Chromatography (GC) according to Wasfi et. al., (2004) \& Seda et. al., (2010).

- Glasgow Coma Scale score: The GCS score consists of three tests: ocular, verbal, and motor responses. The lowest possible total GCS score is 3 (deep coma or death), while the highest is 15 (fully awake person) (Teasdale and Jennett, 1974).

- Treatment: All patients were managed under directions of the center's physicians as follow: 
Correction of acidosis, Folic acid, ethanol as an antidote and hemodialysis according to standards protocol.

4- Statistical analysis: The collected data were computerized and statistically analyzed using SPSS for Windows statistical package, version 16. Quantitative data was expressed as mean and standard deviation (SD). Pearson Chi- Square test was used to compare between groups as regard categorical variables; while MannWhitney U-test was used to compare continuous data. Student t test was used to compare quantitative variables between 2 groups. Pearsons and Spearman Correlation Coefficient was used to find correlation between quantitative variables. In Cox

Table (1): Baseline characteristics, treatment and outcome of patients with acute methanol poisoning:

\begin{tabular}{|l|c|}
\hline \multicolumn{1}{|c|}{ Variable } & Patients (n=51) \\
\hline Age, years* & Matient characteristics \\
\hline Sex & I3.76 $\pm 12.92(22.0-58.0)$ \\
\hline Route of methanol poisoning & Ingestion (100\%) \\
\hline Mode of methanol poisoning & Intentional (100\%) \\
\hline $\begin{array}{l}\text { Alcohol consumption habit } \mathrm{n} \\
(\%)\end{array}$ & Habitual alcohol consumption, 47 (92.2\%) \\
\hline Delay time, hours* & Acute poisoning (100\%) \\
\hline Type of methanol poisoning & $9.05 \pm 2.15(4-13)$ \\
\hline \multicolumn{2}{|c|}{ Clinical findings } \\
\hline GCS score* & $9(19.6 \%)$ \\
\hline Hypothermia, $\mathrm{n}(\%)$ & $9(17.6 \%)$ \\
\hline Hypotension, $\mathrm{n}(\%)$ & $8(15.7 \%)$ \\
\hline Acute respiratory failure, $\mathrm{n}(\%)$ & $5(9.8 \%)$ \\
\hline Arrhythmia, $\mathrm{n}(\%)$ & Laboratory findings \\
\hline Pulmonary edema, $\mathrm{n}(\%)$ & $92.53 \pm 37.85(12-150)$ \\
\hline \multicolumn{2}{|c|}{$6.97 \pm 0.85(6.34-7.4)$} \\
\hline Methanol level, mg/dL* & $27.15 \pm 15.38(12-75.29)$ \\
\hline pH* & $9.29 \pm 3(4$ to 17$)$ \\
\hline$p C O 2, \mathrm{mmHg} *$ & $16.3 \pm 10.31(0$ to 31$)$ \\
\hline Bicarbonate mmol/L* & $30.68 \pm 4.91(20.10-36.60)$ \\
\hline Base deficit, mmol/L* & $34.64 \pm 7.78(28.70-50.36)$ \\
\hline Osmolal gap, mOsm/kg $\mathrm{H}_{2} \mathrm{O}^{*}$ & \\
\hline Anion gap, mmol/L* &
\end{tabular}

regression analysis death was the only dependent variable. Receiver operating characteristic (ROC) curve, area under the curve (AUC), Standardized mortality ratio (SMR) and $95 \%$ CI were calculated. Results considered to be significant when $p$ value $\leq 0.05$.

\section{RESULTS}

1. Patient characteristics and outcome: 51 male, middle aged patients were admitted to emergency department with acute methanol poisoning after a mean latent period of $13.91 \pm 5.42$ hours. The baseline characteristics of the patients at time of admission, treatment and outcome is shown in table (1). 


\begin{tabular}{|l|c|}
\hline Urea nitrogen, mg/dL* & $24.70 \pm 4.30(19-31)$ \\
\hline Serum creatinine, mg/dL* & $1.71 \pm 0.22(1.30-2.09)$ \\
\hline \multicolumn{2}{|c|}{ Treatment modalities } \\
\hline GL n (\%) & $0(0 \%)$ \\
\hline Ethanol n (\%) & $46(90.01 \%)$ \\
\hline Folic acid n (\%) & $51(100 \%)$ \\
\hline Hemodialysis n (\%) & $38(74.5 \%)$ \\
\hline Mechanical ventilation, n (\%) & $12(23.5 \%)$ \\
\hline \multicolumn{2}{|c|}{} \\
\hline livings n (\%) & $30(58.8 \%)$ \\
\hline livings with sequelae n (\%) & $12(23.5 \%)$ \\
Blindness & $5(9.8 \%)$ \\
Diminished vision & $3(5.9 \%)$ \\
Neurological complications & $4(7.8 \%)$ \\
\hline Dead n (\%) & $9(17.6 \%)$ \\
\hline
\end{tabular}

*Values are expressed as mean \pm standard deviation (range).

GCS: Glasgow Coma Scale. pCO2: partial pressure of CO2.CPR:Cardiopulmonary resuscitation. GL: gastric lavage. $n=$ number of patients. $\%=$ percent to total .

2. Analysis of the prognostic factors:

Comparison between livings and dead as regard clinical findings revealed statistical significant differences as regard hypotension, acute respiratory failure, pulmonary edema and GCS score and nonsignificant differences as regard age, latent period, hypothermia and arrhythmia (table 2).

Table (2): Comparison between both livings and dead as regard clinical findings using $\mathrm{t}$ test,

Mann-Whitney U-test \& Pearson Chi- Square test:

\begin{tabular}{|c|c|c|c|c|}
\hline Clinical findings & Livings & Dead & test & $\boldsymbol{P}$ value \\
\hline Age\# $(\mathrm{t}=51)$ & $41.0 \pm 14.03$ & $47.71 \pm 10.9$ & $\mathrm{t}=1.06$ & $0.30^{\circ}$ \\
\hline Latent period\# $(\mathrm{t}=51)$ & $12.75 \pm 5.25$ & $15.57 \pm 5.62$ & $\mathrm{MW}=1.13$ & $0.27^{\circ}$ \\
\hline $\begin{array}{c}\text { Hypothermia }(\mathrm{t}=10) \\
\mathrm{n}(\%)\end{array}$ & $5(50 \%)$ & $5(50 \%)$ & $\chi 2=0.78$ & $0.38^{\circ}$ \\
\hline $\begin{array}{c}\text { Hypotension ( } \mathrm{t}=9) \\
\mathrm{n}(\%)\end{array}$ & $3(33.3 \%)$ & $6(66.7 \%)$ & $\chi 2=5.13$ & $0.02^{*}$ \\
\hline $\begin{array}{c}\text { Arrhythmia ( } \mathrm{t}=8) \\
\mathrm{n}(\%)\end{array}$ & $5(62.5 \%)$ & $3(37.5 \%)$ & $\chi 2=0.08$ & $0.77^{\circ}$ \\
\hline $\begin{array}{c}\text { Acute respiratory } \\
\text { failure (t=9) } \mathrm{n}(\%)\end{array}$ & $3(33.3 \%)$ & $6(66.7 \%)$ & $\chi 2=5.13$ & $0.02^{*}$ \\
\hline $\begin{array}{c}\text { Pulmonary odema } \\
(\mathrm{t}=5) \mathrm{n}(\%)\end{array}$ & $0(0 \%)$ & $5(100 \%)$ & $\chi 2=5.2$ & $0.02^{*}$ \\
\hline GCS score\# (t=51) & $9.71 \pm 1.68$ & $6.0 \pm 1.22$ & $\mathrm{t}=6.24$ & $<0.001^{* *}$ \\
\hline
\end{tabular}

$\#=$ Values expressed as mean \pm standard deviation $n=$ number of cases. $\%=$ percent of number of cases to total number of cases in each parameter. t: total number of cases $\chi 2=$ Pearson Chi- Square test. MW =Mann-Whitney $U$ test. $G C S=$ Glasgow Coma Scale $. t=$ student $\mathrm{t}$ test. $* *$ highly significant. ${ }^{*}$ significant. ${ }^{\circ}=$ not significant. 
As regard laboratory findings, there were statistical significant differences as regard mean values of blood methanol level, $\mathrm{pH}, p \mathrm{CO} 2$, bicarbonate, base deficit, urea nitrogen and serum creatinine whereas, no statistical significant differences was found as regard mean value of osmolal gap and anion gap between livings and dead (table 3).

Table (3): Comparison between both livings and dead as regard laboratory findings using t test \& Mann-Whitney U-test:

\begin{tabular}{|c|c|c|c|c|}
\hline Lab. findings & Livings & Dead & test & $\boldsymbol{P}$ value \\
\hline Methanol level,mg/dl & $80.10 \pm 24.29$ & $110.29 \pm 48.05$ & $\mathrm{t}=1.98$ & $0.04^{*}$ \\
\hline $\mathbf{p H}$ & $7.19 \pm 0.2$ & $6.58 \pm 0.16$ & $\mathrm{t}=8.77$ & $<0.001^{* *}$ \\
\hline $\boldsymbol{p C O 2 , ~} \mathbf{~ m m H g}$ & $23.66 \pm 11.74$ & $43.42 \pm 18.23$ & $\mathrm{MW}=2.92$ & $0.004^{* *}$ \\
\hline Bicarbonate, $\mathbf{~ m m o l} / \mathbf{L}$ & $10.90 \pm 2.96$ & $7.00 \pm 3.00$ & $\mathrm{MW}=2.41$ & $0.01^{*}$ \\
\hline Base deficit, $\mathbf{~ m m o l} / \mathbf{L}$ & $14.04 \pm 9.93$ & $26.8 \pm 2.47$ & $\mathrm{MW}=2.01$ & $0.02^{*}$ \\
\hline Osmolal gap,mOsm/kg H2O & $29.52 \pm 4.15$ & $32.34 \pm 5.74$ & $\mathrm{t}=1.18$ & $0.25^{\circ}$ \\
\hline Anion gap,mmol/L & $33.53 \pm 4.03$ & $36.50 \pm 8.29$ & $\mathrm{t}=1.32$ & $0.21^{\mathbf{o}}$ \\
\hline Serum creatinine mg/dL & $1.61 \pm 0.17$ & $1.84 \pm 0.21$ & $\mathrm{t}=2.47$ & $0.02^{*}$ \\
\hline Urea nitrogen $\mathbf{~ m g / d L}$ & $22.8 \pm 3.58$ & $27.41 \pm 3.94$ & $\mathrm{t}=2.51$ & $0.02^{*}$ \\
\hline
\end{tabular}

GCS= Glasgow Coma Scale. $p C O 2=$ partial pressure of $\mathrm{CO2} . \mathrm{t}=$ student $\mathrm{t}$ test.

MW=Mann-Whitney $U$ test. $* *$ highly significant. $*$ significant. ${ }^{\circ}=$ not significant.

Cox regression analysis revealed that $\mathrm{pH}$, GCS score and $p \mathrm{CO} 2$ were found to be the significant prognostic factors for methanol mortality in the examined subjects. Although base deficit and bicarbonate (reflected the metabolic components of the acidosis) were also associated with mortality but both differences were dependent on $\mathrm{pH}$ as shown in table (4).

Table (4): Factors associated with mortality using Cox regression analysis:

\begin{tabular}{|c|c|c|}
\hline Variable & OR(95\% CI $)$ & $\boldsymbol{P}$-value \\
\hline GCS score & $0.805(0.651-0.962)$ & $0.028^{*}$ \\
\hline Methanol level & $2.5(0.32-19.53)$ & $0.38^{\mathbf{o}}$ \\
\hline PH & $4.765(1.22-17.40)$ & $0.016^{*}$ \\
\hline PCO2 & $0.30(0.12-0.77)$ & $0.004^{*}$ \\
\hline Bicarbonate & $6.75(1.02-44.71)$ & $0.01^{*}$ \\
\hline Base deficit & $6.89(1.22-44.94)$ & $0.01^{*}$ \\
\hline Urea nitrogen & $0.31(0.11-0.63)$ & $0.09^{\mathbf{o}}$ \\
\hline Serum creatinine & $3.11(0.41-23.39)$ & $0.26^{\mathbf{~}}$ \\
\hline
\end{tabular}

OR: odds ratio. $95 \%$ CI: confidence interval. ${ }^{\circ}=$ not significant. *significant.

The ROC curve and the cut off values with the highest sensitivity and specificity for $\mathrm{pH}$, GCS and $\mathrm{pCO} 2$ were shown in figures (1\&2). $\mathrm{pH}$ and GCS score showed higher sensitivities and specificities than $p \mathrm{CO} 2$ as a predictive variable for mortality 


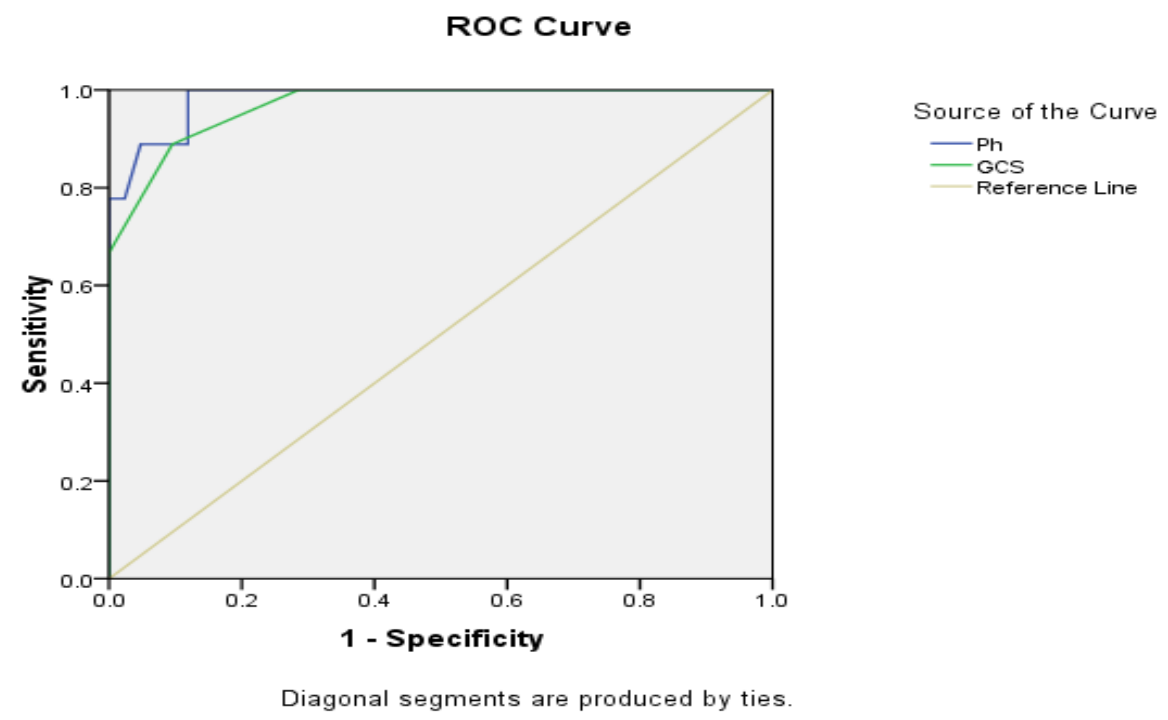

Figure (1): ROC plot showing the ability of $\mathrm{pH}$ and GCS scoring system to predict mortality. $\mathrm{pH}$ at level of 6.79 or lower can predict mortality with 0.889 sensitivity and 0.952 specificity. GCS score at 7 or lower can predict mortality with 0.889 sensitivity and 0.905 specificity in the studied acute methanol poisoned patients.

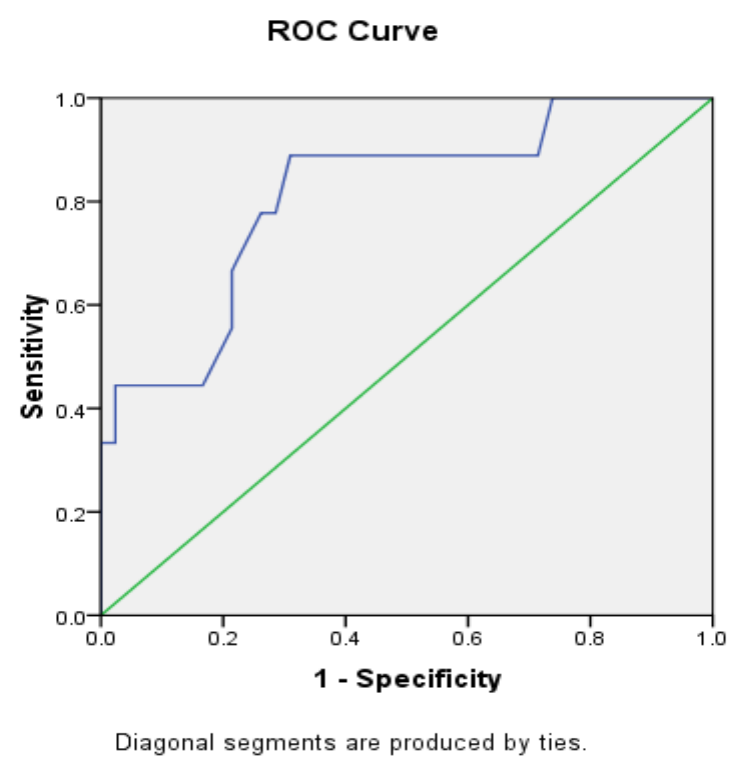

Figure (2): ROC plot showing the ability of $p \mathrm{CO} 2$ to predict mortality at level of $31.88 \mathrm{mmHg}$ or higher with 0.778 sensitivity and 0.738 specificity in the studied acute methanol poisoned patients. 
The AUC for $\mathrm{pH}, \mathrm{GCS}$ and $p \mathrm{CO} 2$

with the cut off value for each variable

were shown in table (5).

Table (5): The AUC for $\mathrm{pH}, \mathrm{GCS}$ and $\mathrm{pCO} 2$ with the cut off value for each variable:

\begin{tabular}{|c|c|c|c|c|}
\hline Variable & Cut off value & AUC \pm Std. Errorr ${ }^{a}$ & $P$-value & $95 \% \mathrm{CI}$ \\
\hline $\mathrm{pH}$ & 6.79 & $0.983 \pm 0.016$ & $<0.001^{* *}$ & $0.952-1.014$ \\
\hline GCS score & 7.5 & $0.968 \pm 0.025$ & $<0.001 * *$ & $0.919-1.017$ \\
\hline$P C O 2 \mathrm{mmHg}$ & 31.88 & $0.812 \pm 0.081$ & $0.004 * *$ & $0.653-0.971$ \\
\hline
\end{tabular}

GCS: Glasgow Coma Scale. $* *$ Highly significant. $95 \%$ CI: confidence interval. GCS= AUC: Area under the curve

A non-significant correlation was found between $\mathrm{pH}$ versus $p \mathrm{CO} 2$ values in dead $(p>0.05)$ indicating decreased

ability to compensate for metabolic acidosis by hyperventilation (fig.3).

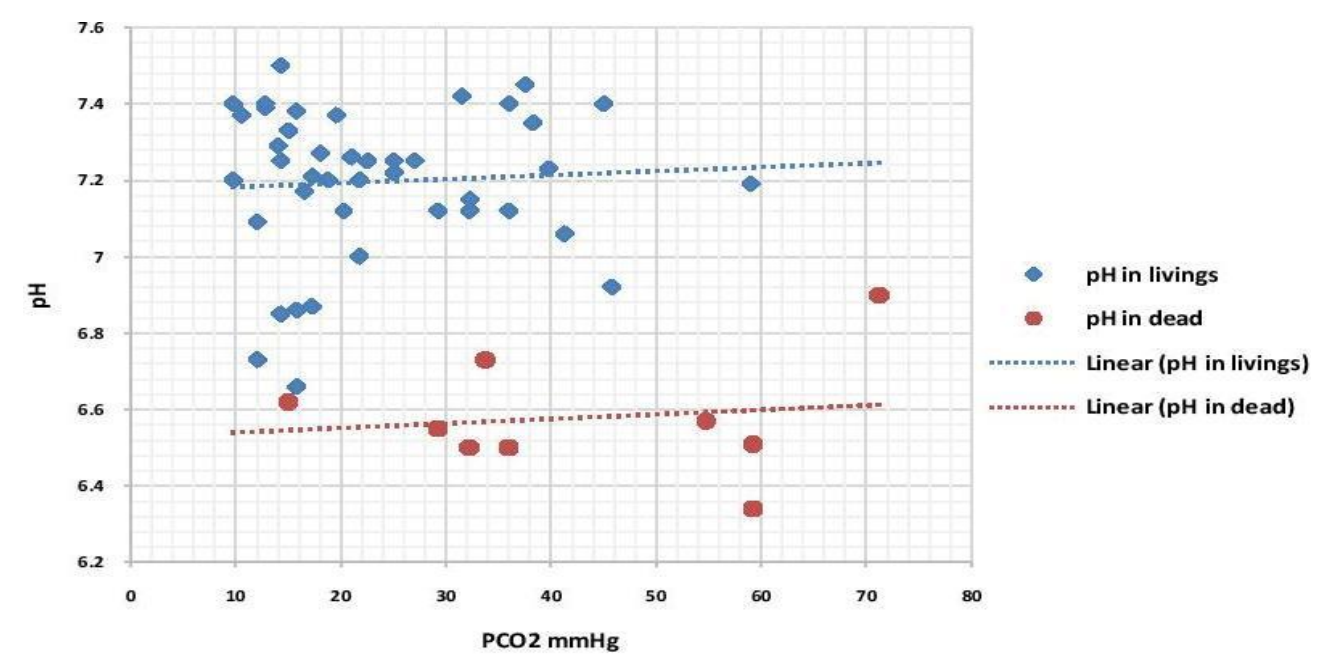

Figure (3): Scatter diagram showing correlation between $\mathrm{pH}$ and $p \mathrm{CO} 2$ in both livings $(\mathrm{r}=-0.040, p=0.80)$ and dead $(\mathrm{r}=-0.025, p=0.95)$.

When the expected mortality by GCS scoring system $(15.7 \%)$ and the observed mortality in the studied patients $(17.6 \%)$, there was a nonsignificant difference between them with standardized mortality ratio (SMR) of 1.13 and $95 \%$ CI of 0.39 1.87 and $p>0.05$.

\section{DISCUSSION}

Methanol toxicity is considered a problem in many parts of the developing countries especially between people in low socioeconomic levels (Ghanem et. al., 2015). Methanol poisoning in Egypt still have a poor outcome because of the late arrival and diagnosis of the patients in addition to the unavailability of blood methanol level in many hospitals and the high price of fomepizole (Rezk \& Allam, 2009). Diagnosis is based on history, signs, symptoms and the following laboratory findings: metabolic acidosis, elevated anion gap and/or osmolal gap (Sharma et al., 2012).

The current study was carried on 51 middle aged male patients chosen according to specific inclusion criteria. Regarding the clinical findings; hypotension, acute respiratory failure, pulmonary edema and low GCS score on admission were associated with high mortality. 
As regard laboratory findings, dead had a statistically significant higher blood methanol level and lower $\mathrm{pH}$ than livings. $\mathrm{PCO} 2$ as well as serum creatinine and urea nitrogen were found to be highly significantly increased in dead.

A wide discrepancy in blood methanol levels were noticed in many previous studies; Shadnia et. al., (2013) who reported a highly statistically significant methanol levels in dead when compared to survivors. On the other hand, Hovda et. al., (2005) found that although blood methanol levels were higher in dead than in livings, in comparison a nonsignificant differences were reported. (Paasma et. al., 2007) reported the higher means of serum methanol levels in the survivors with complications followed by the dead while the survived cases with no complications were the least. This discrepancy in blood methanol levels could be attributed to the followings; first; the retrospective design of the previously mentioned studies with its limitation. Second; the variations in treatment modalities. Third; combined ethanol and methanol which were taken by patients in these studies. That differed from the current study in being prospective study, all the cases were evaluated at admission prior to any treatment and all patients included in this study took only methanol.

$\mathrm{pH}$, GCS score and $p \mathrm{CO} 2$ were significantly associated with mortality by Cox-regression with high sensitivities and specificities by ROC curve and AUC. When ranking the risk factors, $\mathrm{pH} \leq 6.79$ was the most important parameter followed by GCS score $\leq 7$ then $p \mathrm{CO} 2 \geq 31.88 \mathrm{mmHg}$.

These results were consistent with Coulter et. al., (2011) \& Kute et. al.,
(2012) who stated that mortality was increased with increasing severity of metabolic acidosis. Paasma et al. (2012) concluded the strongest predictors of poor outcome after methanol poisoning to be; low $\mathrm{pH}(\mathrm{pH}$ <7), coma (GCS score <8) and inadequate hyperventilation ( $p \mathrm{CO} 2$ $>3.1$ kilopascal in spite of a $\mathrm{pH}<7$ ) on admission. Furthermore, Lee et. al., (2014) found that GCS score was one of the strongest risk factors associated with mortality. Zakharov et. al., (2017) stated that the probability of bad outcome (death or complications) decreased with decreasing severity of metabolic acidosis. Shadnia et. al., (2013) stated that coma, respiratory depression, $\mathrm{PCO} 2$ were strong predictors of poor outcome but, on the other hand they reported a nonsignificant difference in blood $\mathrm{pH}$ between survivor and non-survivor groups and stated that blood $\mathrm{H}+$ concentration is regulated by $\mathrm{PCO} 2$ and bicarbonate, so it depended on the compensatory situations of each patient, this study is retrospective and the number of patients is relatively small, which could be considered as a limitation of this study.

Moreover, in a study by Rezk \& Allam (2009) entailed methanol poisoned patients admitted to the poison control centre, Ain Shams University, Egypt in one year and recorded that, mortality was much more prevalent among those who suffered from metabolic acidosis.

The importance of lack of respiratory compensation with respect to the outcome of patients was first reported by Hovda et. al.,(2005), Paasma et. al., (2007) and later by Hassanian-Moghaddam et. al., (2007). 
In this study the dead patients have lower $\mathrm{pH}$ values with higher levels of $p \mathrm{CO} 2$ and a negative correlation was found between $\mathrm{pH}$ and $p \mathrm{CO} 2$ which indicated lack of respiratory compensation that may be attributed to acute respiratory failure or pulmonary edema which had a higher incidence in dead patients or the CNS-depression evidenced by lower GCS score.

Hovda et. al., (2005) reported an inverse correlation between $\mathrm{pH}$ and pCO2 which can be explained by the co-ingestion of ethanol that caused more CNS depression and eventually loss of respiratory drive and more worsening of $\mathrm{pH}$. The ability of acute methanol poisoning patients with metabolic acidosis to hyperventilate is alarm of avoiding normo-ventilation after they were put on a ventilator or a fatal worsening of the acidosis will occur (Paasma et al.,2012).

\section{CONCLUSION}

From the result of this study we can conclude that Hypotension, acute respiratory failure and pulmonary edema were robust markers of mortality in the studied acute methanol poisoned patients along with $\mathrm{pH} \leq 6.79$, GCS score $\leq 7$ and $p \mathrm{CO} 2 \geq 31.88 \mathrm{mmHg}$. GCS scoring system was found to detect those patients who were at risk so, GCS scoring system could be an easy predictive model in acute methanol poisoning. This study is a pilot study, larger scale studies over several years is recommended to validate the results.

\section{REFERENCES}

Coulter, C.V.; Farquhar, S.E.; McSherry, C.M.; Isbister, G.K. \& Duffull, S.B. (2011): Methanol and ethylene glycol acute poisonings -predictors of mortality. Clin Toxicol (Phila), 49: 900-906.

Davies, J.O.J.; Eddleston, M. \& Buckley, N.A. (2008): Predicting outcome in acute organophosphorus poisoning with a poison severity score or the Glasgow coma scale. QJM ,101:371-379.

Ghanem, M.; Mohamed, A.; Salama, N. \& Abd El-Hamied, S.E. (2015): Adaptation of international guidelines for management of methyl alcohol poisoning in patients admitted to the poisoning unit in Alexandria main university hospital. Tanta Medical Journal, 43:89-93.

Giovanetti, F. (2013): Methanol poisoning among travellers to Indonesia. Travel Medicine and Infectious Disease, 11:190-193.

Grieb, G.; Simons, D.; Schmitz, L.; Piatkowski, A.; Grottke, O. \& Pallua, N. (2011): Glasgow coma scale and laboratory markers are superior to $\mathrm{COHb}$ in predicting $\mathrm{CO}$ intoxication severity. Burns, 4: 610-615.

Hassanian-Moghaddam, H. ; Pajoumand, A. ; Dadgar, S.M. \& Shadnia, S. (2007): prognostic factors in methanol poisoning. Hum Exp Tox, 7: 583- 586.

Hovda K.E.; Hunderi, O.H.; Tafjord, A.B.; Dunlop, O., Rudberg, N. \& Jacobsen D. (2005): methanol outbreak in Norway20022004:epidemiology, clinical features and prognostic signs. J Int Med, 2:181-90.

Kute, V.B.; Godara, S.M.; Shah, P.R.; Gumber, M.R.; Goplani, 
K.R.; Vanikar, A.V.; et al. (2012): Hemodialysis for methyl alcohol poisoning: a single-center experience. Sau J Kid Dis Transp, 1:37-43.

Lee, C.Y.; Chang, E.K. \& Lin, J. (2014): risk factors for mortality in Asian Taiwanese patients with methanol poisoning. Ther Clin Risk Manag, 10:61-7.

Paasma, R. ; Hovda, K. E.; Tikkerberi, A. \& Jacobsen, D. (2007): methanol mass poisoning in Estonia: outbreak in 154 patients. Clin Tox (Phila), 2:152-157.

Paasma, R.; Hovda, K.E.; Moghaddam, H.H.; brahmi, N.; Afshari, R.; Sandvik L. \& Jacobsen D. (2012): Risk factors related to poor outcome after methanol poisoning and the relation between outcome and antidotes- a multicenter study. Clinical Toxicology, 50: 823-831.

Pohanka, M. (2016): Toxicology and the biological role of methanol and ethanol: Current view. Biomed Pap Med Fac Univ Palacky Olomouc Czech Repub, 1:54-63.

Rezk, N. \& Allam, M. (2009): Fatal Prognosis of Methanol Toxicity: Identification of Predictive Factors. Med J Cairo Univ, 77:101-105.

Seda, K.; Ayse, K.; Görkem M.; Emrah, D.; Vugar, A.; Serap, Y.; Tülin, S. \& Zeliha, K. (2010): simultaneous headspace-GC-FID analysis for methanol and ethanol in blood, saliva, and urine: validation of method and comparison of specimens. L.C.G.C. North America, 7: 540-543.

Shadnia, S.; Rahimi, M.; Soltaninejad, K. \& Nilli, A. (2013): Role of clinical and paraclinical manifestations of methanol poisoning in outcome prediction. J Res Med Sci, 18: 865869.

Shah, S.; Pandey, V.; Thakore, N. \& Mehta, I. (2012): study of 63 Cases of Methyl Alcohol Poisoning (Hooch Tragedy in Ahmedabad). J Assoc Phys Ind, 60: 34-6.

Sharma, R.; Marasini, S.; Sharma, A.K.; Shrestha J.K. \& Nepal B.P. (2012): methanol Poisoning: Ocular and Neurological Manifestations. Optom and Vis Sci, 2: 178-182.

Wasfi, I.A.; Al-Awadhi, A.H.; AlHatali, Z.N.; Al-Rayami, F.J. \& Al Katheeri, N.A. (2004): Rapid and sensitive static headspace gas chromatography-mass spectrometry method for the analysis of ethanol and abused inhalants in blood. J Chrom B Analyt Tech Bio Life Sci, 2:331-336.

Zakharov, S.; Nurieva, O.; Kotikova, K.; Belacek, J.; Navratil, T. \& Pelclova, D. (2017): Positive serum ethanol concentration on admission to hospital as the factor predictive of treatment outcome in acute methanol poisoning. Monatsh Chem, 148:409-419. 


\section{التسمم الحاد بالكحول الميثيلي : عوامل الخطوره ودور معيار جلاسكو}

غادة نبيل منصور 1, محمد عبدالرحمن عجلان 2, محمود بدر عبدالوهاب3

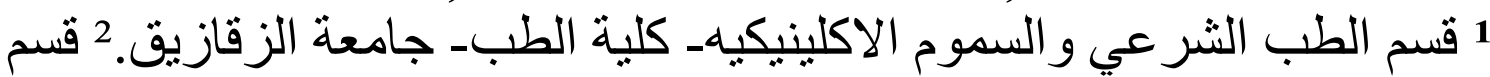

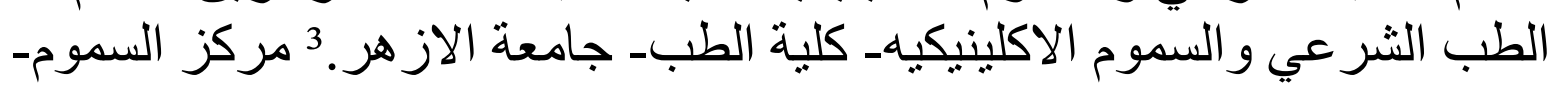
مستشفيات جامعه عين شمس كله

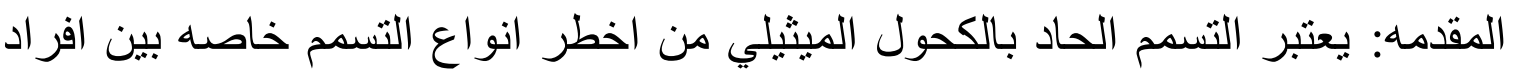

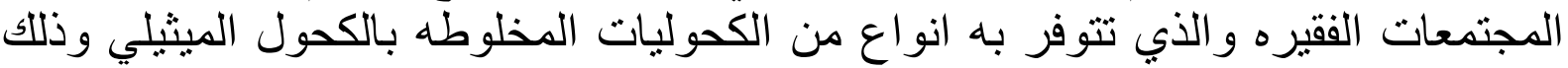

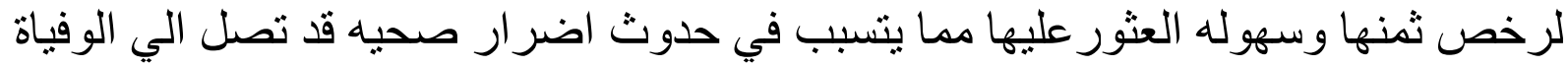

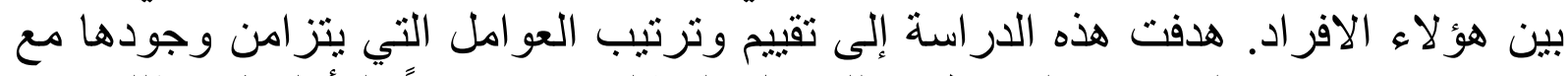

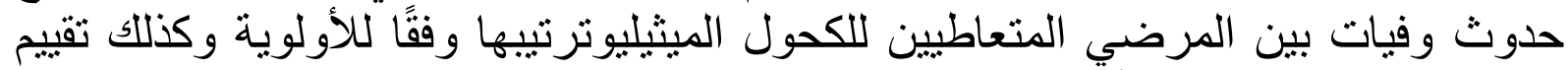

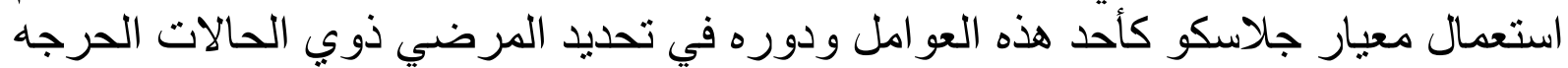

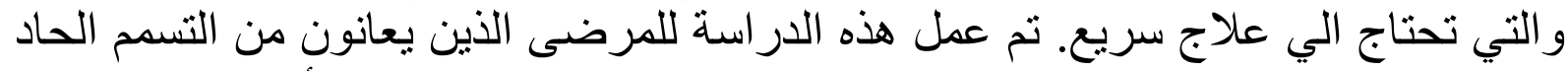

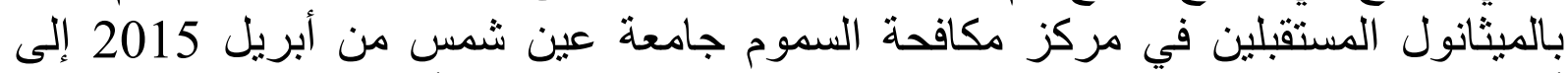

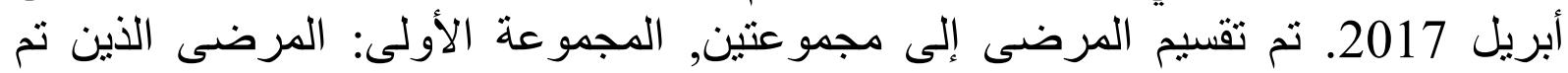

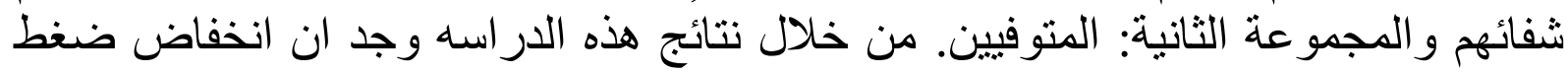

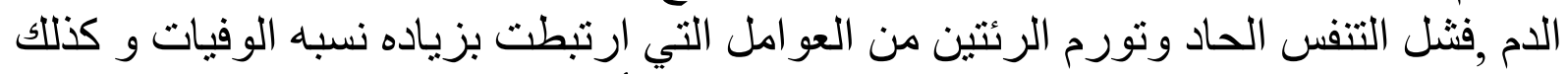

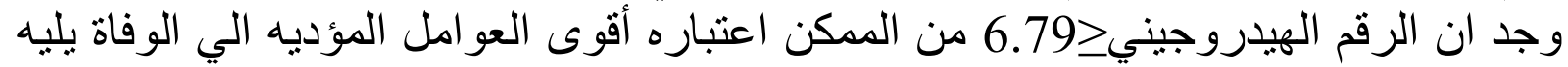
معيار جلاسكو ج 7.5 وفي النهاية 